\title{
How Can Music Influence the Autonomic Nervous System Response in Patients with Severe Disorder of Consciousness?
}

\author{
Francesco Riganello *, Maria D. Cortese, Francesco Arcuri, Maria Quintieri and \\ Giuliano Dolce
}

Research in Advanced Neurorehabilitation, Istituto S. Anna, Crotone, Italy

\section{OPEN ACCESS}

Edited by:

Caroline Schnakers,

University of California, Los Angeles,

USA

Reviewed by:

Lizette Heine,

University of Liège, Belgium

Aurore Thibaut,

University of Liège, Belgium

*Correspondence:

Francesco Riganello

f.riganello@istitutosantanna.it

Specialty section:

This article was submitted to Auditory Cognitive Neuroscience,

a section of the journal

Frontiers in Neuroscience

Received: 01 July 2015 Accepted: 20 November 2015 Published: 10 December 2015

Citation:

Riganello F, Cortese MD, Arcuri F, Quintieri M and Dolce G (2015) How

Can Music Influence the Autonomic Nervous System Response in Patients with Severe Disorder of Consciousness?

Front. Neurosci. 9:461 doi: 10.3389/fnins.2015.00461
Activations to pleasant and unpleasant musical stimuli were observed within an extensive neuronal network and different brain structures, as well as in the processing of the syntactic and semantic aspects of the music. Previous studies evidenced a correlation between autonomic activity and emotion evoked by music listening in patients with Disorders of Consciousness (DoC). In this study, we analyzed retrospectively the autonomic response to musical stimuli by mean of normalized units of Low Frequency (nuLF) and Sample Entropy (SampEn) of Heart Rate Variability (HRV) parameters, and their possible correlation to the different complexity of four musical samples (i.e., Mussorgsky, Tchaikovsky, Grieg, and Boccherini) in Healthy subjects and Vegetative State/Unresponsive Wakefulness Syndrome (VS/UWS) patients. The complexity of musical sample was based on Formal Complexity and General Dynamics parameters defined by Imberty's semiology studies. The results showed a significant difference between the two groups for SampEn during the listening of Mussorgsky's music and for nuLF during the listening of Boccherini and Mussorgsky's music. Moreover, the VS/UWS group showed a reduction of nuLF as well as SampEn comparing music of increasing Formal Complexity and General Dynamics. These results put in evidence how the internal structure of the music can change the autonomic response in patients with DoC. Further investigations are required to better comprehend how musical stimulation can modify the autonomic response in DoC patients, in order to administer the stimuli in a more effective way.

Keywords: disorder of consciousness, vegetative state, autonomic nervous system, central autonomic network, heart rate variability, music therapy, entropy

\section{INTRODUCTION}

Music listening is one of the most pleasurable experiences for the human being (Dube and Le Bel, 2003). Music can be defined as the organization of the tone over the time. By mean of the exposure to musical pieces in everyday life, listeners acquire sensitivity to the regularities of the tonal system (Tillmann, 2005). This knowledge creates expectancy in the listeners, with experience of tension, suspense or relaxation, when the rules are confirmed, or violated (Meyer, 2008; Ockelford, 2008). Activations to pleasant and unpleasant musical stimuli were observed within an extensive 
neuronal network of limbic and paralimbic brain structures. Activations in the ventral striatum, anterior superior insula, and in Rolandic operculum were observed in healthy subjects, during the listening of pleasant music (Koelsch et al., 2006). Moreover, inferior frontolateral cortex, ventrolateral premotor cortex, and anterior part of the superior temporal gyrus were found active in the processing of musical syntax, whereas the processing of musical semantics appears to activate posterior temporal regions (Koelsch, 2005).

Some studies also evidenced a correlation between autonomic activity (modulation of the High frequency component recorded by Heart Rate Variability), and emotion evoked by musical listening (Iwanaga et al., 2005; Orini et al., 2010).

The emotions felt by the listening to music were described as linked to the musical structures (Juslin and Sloboda, 2010). The parameters, defined as Formal Complexity and General Dynamics, provide informations about the relationship between musical structures and emotions (Imberty, 1976). Imberty defines Formal Complexity and General Dynamics, combining musical variables (as note duration, metric interval, density of notes per time unit, loudness, accents, syncopation and other characteristics of melodic, harmonic, and rhythmic structures) associating them to the emotion induced by the music (Imberty, 1976, 1997). In particular, the General Dynamics is defined as the number per time unit of notes played and their relative intensity, while the Formal Complexity as the intrinsic homogeneity of the musical structures (i.e., melodic recorsivity, rhythmic structure, dissonance etc; Table 1).

The emotional reactions to four musical samples of different complexity [Boccherini: Minuet; Grieg: Morning; Tchaikovsky: Pathetic (1st movement), and Mussorgsky: Night on bald mountain] were observed in Traumatic Brain Injured (TBI) patients and healthy subjects by mean of the Heart Rate Variability (HRV) analysis, with a classification of reported emotions by the normalized unit of the low frequency (nuLF; Riganello et al., 2008). Successively, it has been possible to infer positive and negative emotional responses in Vegetative State/Unresponsive Wakefulness Syndrome (VS/UWS) patients (Riganello et al., 2010a), undergone to the same experimental

TABLE 1 | Descriptors of music formal complexity and general dynamics.

\begin{tabular}{|c|c|}
\hline Formal complexity & General dynamics \\
\hline$\left(H m^{*} t\right) \pm\left(e l^{*} e R\right)$ & $V^{*} \mid$ \\
\hline $\begin{array}{l}\left(\mathrm{Hm}^{*} \mathrm{t}\right)=\text { structure homogeneity index } \\
\left(\mathrm{e} \mathrm{l}^{*} \mathrm{e}\right)=\text { Heterogeneity index } \\
\mathrm{Hm}=\text { melodic entropy computed on the } \\
\text { epoch of music with melody } \\
\mathrm{t}=\text { duration of metric interval } \\
\text { el = mean variation in intensity of each note } \\
\text { over the time } \\
\text { eR = mean variation of duration }\end{array}$ & $\begin{array}{l}V=\text { mean number of successive } \\
\text { musical note per second } \\
I=\text { subjective intensity }\end{array}$ \\
\hline
\end{tabular}

Musical structure are characterized by means of the available descriptors of formal complexity and heterogeneity index (or intrinsic homogeneity; FC) and general dynamics (GD). FC describes the intrinsic organization and "predictability" of the music as to rhythm or melody or its lack of perceivable structure and is conventionally regarded as an index of emotional sympathy. GD describes the music in terms of volume, harmony, and rhythms and reportedly accounts for motor involvement. Different degree of FC and GD inducing to different emotional status. procedure, in particular when they were exposed to the Boccherini's music (positive emotion) and to the Mussorgsky's music (negative emotion).

In the HRV analysis, the data are analyzed in time, frequency, and non-linear domains (Task Force of the European Society of Cardiology the North American Society of Pacing Electrophysiology, 1996; Riganello et al., 2012b). In the time domain, HRV measures are mainly markers of overall HRV. Detailed informations on the HRV dynamics and frequency components are provided by the analysis in the frequency domain by Fast Fourier Transform (FFT) or autoregressive (AR) models (Malliani, 1999; Montano et al., 2009). The generalized frequency bands, in case of short-term HRV recordings, are the very low frequency (VLF: 0-0.04 Hz), low frequency (LF: $0.04-0.15 \mathrm{~Hz}$ ), and high frequency (HF: $0.15-0.5 \mathrm{~Hz}$ ). Specifically, normalized unit of Low Frequency (nuLF; Burr, 2007), computed as second step after the initial statistical estimation of the power in the Low Frequency and High Frequency bands $[\mathrm{nuLF}=\mathrm{LF} /(\mathrm{LF}+\mathrm{HF})]$, is deemed indicative of sympathovagal balance.

All frequency domains analyses are based on the recognition of certain predetermined patterns (in FFT the pattern is a sinusoidal wave). A possible alternative to characterize the variability of heart rate is to measure the regularity (or complexity) of the fluctuations. The entropy (non-linear analysis metrics) is a general approach to quantify the regularity or information content of the data, providing "hidden information" related to underlying mechanisms (Richman and Moorman, 2000). The Approximate Entropy (ApEn; Pincus and Goldberger, 1994) determines the conditional probability of similarity between a chosen data segment and the next set of segments of the same duration. ApEn has been developed for measuring the complexity of relatively short time series and the calculations are not based on specific assumptions regarding the internal structure or dynamics of the system. However, ApEn has some known shortcomings, such as bias, relative inconsistency, and dependence on the sample length. Sample Entropy (SampEn) reduces the bias of ApEn (Aboy et al., 2007) is more consistent and easier to compute than ApEn, and provides a more reliable estimate of the complexity of a signal. Moreover, it may be used for considerably shorter time series than the ApEn, ( $<200$ points; Batchinsky et al., 2009).

Heart rate complexity data (entropy) reflect overall balance of autonomic outflow, responsiveness, and neuroendocrine mechanisms (Ryan et al., 2011; Riganello et al., 2012a,b). Decreased variability is thought to reflect system isolation and a reduced ability to respond to perturbations. Entropy analysis represents potential powerful methods to use in the care for critically ill patients. In Intensive Care Unit reduced entropy was associated with illness and predicts death (Papaioannou et al., 2006, 2008; Riordan et al., 2009). The changes of entropy rates have been mainly related to aging and disease (Kaplan et al., 1991; Voss et al., 1996). More, it has been suggested that the complexity of short-term recording of heart rate variability might be closely related to cardiac autonomic modulation (Porta et al., 2000).

The decreased entropy of heart rate complexity, associated with Lifesaving Interventions in both prehospital trauma (Cancio et al., 2008) and Cardiac Autonomic Neuropathy patients, 
suggests a reduced responsiveness of the cardiac control mechanism to external and internal stimuli (Khandoker et al., 2009). The reduced entropy was significantly associated with an increase of mortality, and a relationship between entropy and death was found in patients with isolated severe head injury and with penetrating mechanisms of injury (Riordan et al., 2009).

Reported studies put in evidence the effectiveness of HRV analysis related to the autonomic nervous system (ANS) modifications. The children, who progressed to brain death, had a markedly lower LF/HF ratio, while the patients with more favorable outcomes had significantly higher LF/HF ratios (Biswas et al., 2000). As reported, a worsening of the conditions in TBI patients was correlated to the LF, the severity of neurological dysfunctions and the outcome, as well as the global HRV and parasympathetic tone were found higher in TBI patients, successively died (Goldstein et al., 1996; Rapenne et al., 2001; Norris et al., 2006). On the contrary, an amelioration was correlated to the recovery of autonomic functions, with a decrease of the parasympathetic activity, and a parallel recovery of the consciousness (Keren et al., 2005; Wijnen et al., 2006).

Many studies evidenced the different responses of the ANS, recorded by the HRV analysis, due to the different music styles. Different complex heart dynamics responses were observed, during the listening of different Indian Raga musics, assuming possible different responses based on the different musical patterns (Mukherjee et al., 2015). The effects of Iranian music on the cardiac function has been also studied (Hajizadeh et al., 2015), showing increasing values in the SampEn. Other studies suggest that excitative music decreases the activation of the parasympathetic nervous system in healthy subjects (Iwanaga et al., 2005), as well as the excitatory heavy metal music acutely decreases global HRV (da Silva et al., 2014). Exploring different styles of "relaxing" music, the "new age" music induced a shift in HRV from higher to lower frequencies, independently on the music preference of the listener (Perez-Lloret et al., 2014).

Previous studies (based on the analysis of the first 300 heartbeats recorded) have been designed to verify the possibility to classify positive or negative emotions elicited by different musical stimuli selected for their General Dynamics and Formal Complexity (Riganello et al., 2008), and their possible emotional effect in VS/UWS patients (Riganello et al., 2010a). The aim of this study was to verify the influence of the musical stimuli complexity on the autonomic responses in VS/UWS patients, by the HRV nuLF and SampEn parameters analysis during the listening of the first $3 \mathrm{~min}$ of the selected musical samples. The two musical samples (Boccherini and Mussorgsky; Riganello et al., 2010a) have been compared by the nuLF and SampEn parameters, taking in account the possible different effect observed in the VS/UWS patients. The hypothesis is that music with high Formal Complexity and General Dynamics reduces the autonomic response in VS/UWS patients.

\section{MATERIALS AND METHODS}

The first $3 \mathrm{~min}$ of tachogram (i.e., the series of consecutive intervals between heartbeats) recorded during the listening of four musical samples [Boccherini (Minuet); Grieg (The morning); Tchaikovsky (Pathetic-1st movement); and Mussorgsky Night on bald mountain (Figure 1)], by Healthy subjects and VS/UWS patients, were retrospectively analyzed by Kubios HRV version 2.2 (Tarvainen et al., 2014). The selection was characterized by the Formal Complexity and the General Dynamics of the musical samples, as indicated by Imberty (Imberty, 1976, 1997; Juslin and Sloboda, 2010; Table 1; Figure 2). These descriptors are related to the musical structure and allow to characterize the (induced) emotional status along a continuum from euphoria and well-being to melancholy, severe anxiety etc. In particular an increasing of the Formal Complexity is associated to a major shift from "positive" toward "negative" emotions. In general, positive and negative emotions are associated to relatively simple or complex melodies and regular or irregular rhythms, respectively (Vitz, 1966; Crozier, 1974; Holbrook and Anand, 1990; Smith and Melara, 1990); slow and fast tempi are related to the ratings of subjective sadness and joy (Hodges, 1980; Gabrielsson and Juslin, 1996; Juslin, 1997, 2000). A matrix of the music Formal Complexity and General Dynamics was designed to classify the emotional responses and correlate them with the musical structures (see for detail Riganello et al., 2008; Figure 2).

Sixteen healthy subjects ( 9 women, $24-42$ years, mean $31.8 \pm$ 5.2) listened passively the music one time, while 9 patients (6 male, $16-31$ years, mean: $26 \pm 6.0$; 3 female, $31-48$ years, mean: $39 \pm 9$ ) in VS/UWS (Table 2) according to current criteria (Giacino et al., 2004; Giacino and Kalmar, 2005), listened the music twice. All patients were assessed by Coma Recovery Scale Revised (CRS-R) administered by an expert neuropsychologist. The experiments took place always at the same time of the day (within 60 days from the injury), in the semi-intensive care unit dedicated to the vegetative state (the VS/UWS subjects' usual environment) and did not interfere with the patients' medical/rehabilitative schedule. VS/UWS subjects and healthy controls were comfortably lying on armchair, with constant $24^{\circ} \mathrm{C}$ ambient temperature and in absence of transient noises. The baseline was recorded at rest; subjects were exposed binaurally to the four selected music samples, presented via earplugs, balanced for loudness and played in random sequence to minimize carriedover effects. The music samples were presented in randomized sequence with $10 \mathrm{~min}$ of interval between each other. The VS/UWS patients were exposed to two music samples per day only in order to avoid overstimulation and excessive fatigue (for procedures detail see Riganello et al., 2010a).

The tachogram was analyzed in the time and frequency domains, by the HRV advanced analysis software developed at the Department of Applied Physics, University of Kuopio, Finland (Niskanen et al., 2004). The HRV nuLF and SampEn parameters were extracted for the analysis. Each couple of listening of the same musical sample administered to the VS/UWS patients, was averaged in one to avoid the error of alpha inflation in the sample size.

Healthy subjects vs. VS/UWS patients were compared between them for baseline and musical samples by MannWhitney's exact test. Difference among music samples was analyzed by Friedman's exact test and difference between Boccherini and Mussorgsky's music was analyzed by Wilcoxon's 


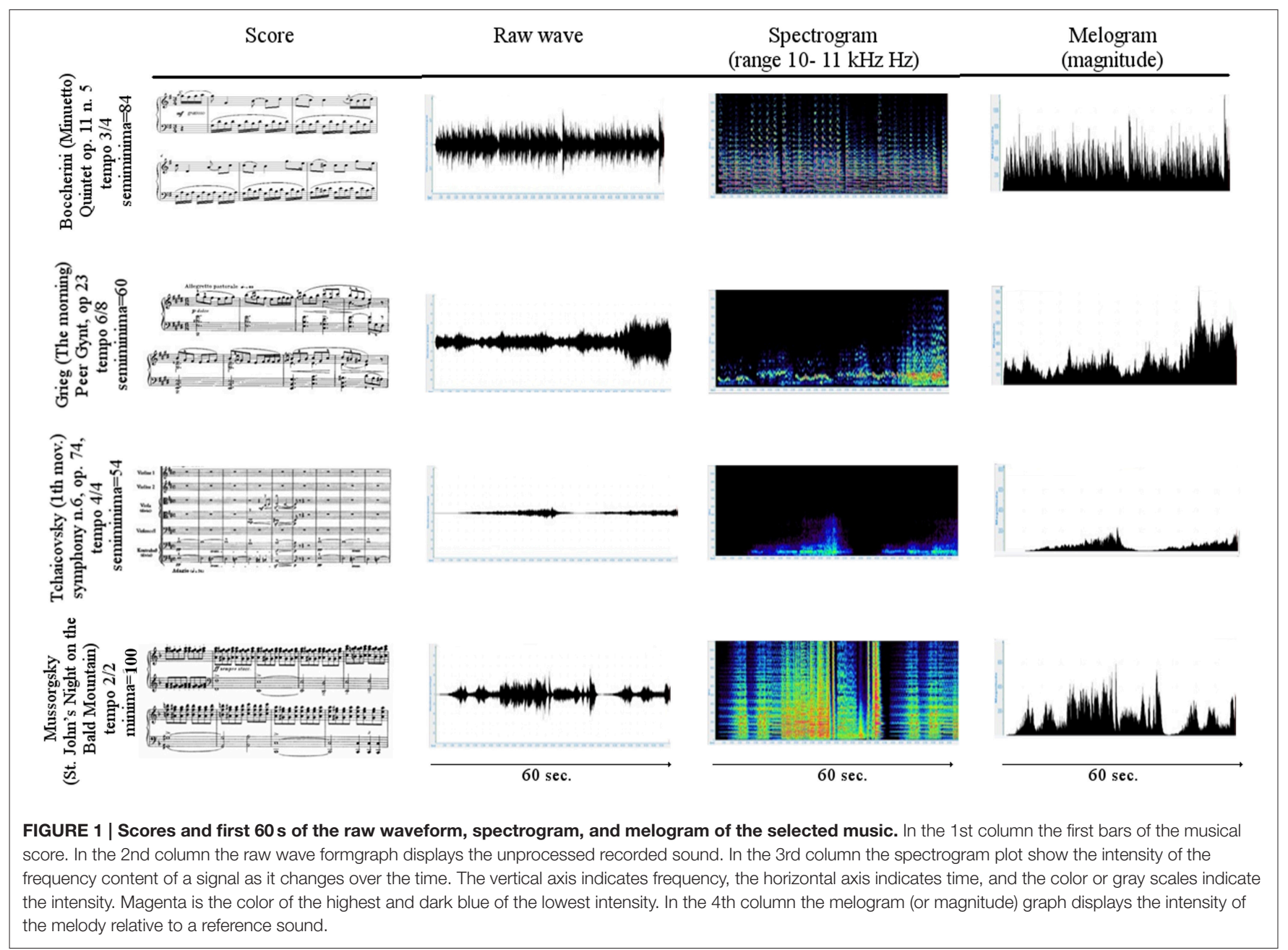

exact test in both groups. The exact test (Siegel, 1956; Gibbons and Chakraborti, 2011) is more accurate in case of small sample, or when the tables are sparse or unbalanced (Tanizaki, 1997; Mundry and Fischer, 1998; Gibbons and Chakraborti, 2011). The effect size $(r)$ i.e., the index measuring the magnitude of difference or change between two conditions, (Rosenthal, 1991) was calculated as the $z$ /square $\operatorname{root}(N$; where $N$ is the number of observations on which $z$ is based) and will be hereafter formally referred to as not relevant $(r<0.1)$, small $(0.1<r<0.3)$, medium $(0.3<r<0.5)$, or large $(r>0.5$; Hemphill, 2003). After the Bonferroni's corrections for multiple comparisons the results of the tests was considered significant for $p$-value $\leq 0.005$.

The ethical principles of the Declaration of World Medical Association (2001) by the World Medical Association were followed.

\section{RESULTS}

After Bonferroni correction no significant difference was found in the baseline condition between groups.

The values of nuLF were found different between groups for Grieg (Mann-Whitney's exact test: $Z=-2.887, p=0.001$, $r=0.58$ ) and Mussorgsky's music (Mann-Whitney's exact test:
$Z=-3.170, p=0.000, r=0.63$ ), while after Bonferroni correction, SampEn was found different only for Mussorgsky's music (Mann-Whitney's exact test: $Z=-3.453 p=0.000, r=$ $0.69)$.

The difference among musical stimuli was significant in VS/UWS group for nuLF (Friedman's exact test: $\chi^{2}=10.733$, $p=0.009$ ) and SampEn (Friedman's exact test: $\chi^{2}=16.067$, $p=0.000$ ) parameters. Comparing Boccherini and Mussorgsky's music, after Bonferroni correction, a significant difference was found for SampEn (Wilcoxon's exact test: 2.668, $p=0.002$, $r=0.63$; Figure 3).

\section{DISCUSSION}

The HRV analysis, of the previous study, was based on the first 300 heartbeats rate recorded (Riganello et al., 2010a), with different times of recording related to the subjects variability. The listening of Boccherini, compared with the other composers, showed a decreasing of the hearth rate. More, it was observed a difference in the nuLF between the baseline and the music samples listening. The nuLF was linked, by data mining analysis, to the emotions evoked by the different music 


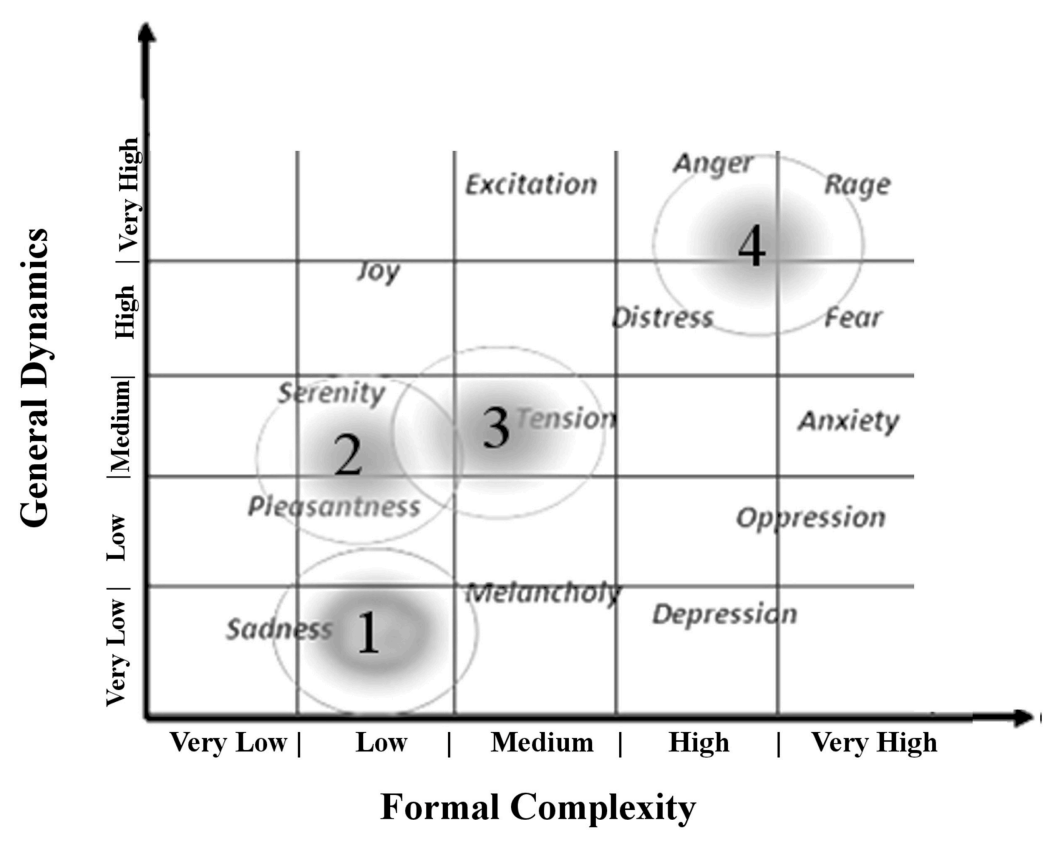

FIGURE 2 | Distribution of reported emotional responses of healthy subjects according to the music general dynamic and formal complexity (see Table 1). Numbers indicate the position in summary outline of the music samples used as auditory stimuli in the study $(1=$ Tchaikovsky; $2=$ Boccherini; $3=$ Grieg; 4 = Mussorgsky). Figure adapted from Riganello et al. (2010a).

TABLE 2 | Demographic data of VS/UWS patients.

\begin{tabular}{|c|c|c|c|c|c|c|}
\hline & Age & Sex & Etiology & CRS-R & CRS-R sub scores & Follow-up at 6 month \\
\hline 1 & 16 & male & traumatic & 6 & $\mathrm{~A}=1 \mathrm{~V}=2 \mathrm{M}=1 \mathrm{O}=1 \mathrm{C}=0 \mathrm{Ar}=1$ & MCS \\
\hline 2 & 21 & & & 5 & $\mathrm{~A}=0 \mathrm{~V}=1 \mathrm{M}=1 \mathrm{O}=1 \mathrm{C}=0 \mathrm{Ar}=2$ & VS \\
\hline 3 & 30 & & & 4 & $\mathrm{~A}=\mathrm{OV}=1 \mathrm{M}=1 \mathrm{O}=1 \mathrm{C}=0 \mathrm{Ar}=1$ & dead \\
\hline 4 & 30 & & & 5 & $A=1 \mathrm{~V}=1 \mathrm{M}=1 \mathrm{O}=1 \mathrm{C}=0 \mathrm{Ar}=1$ & VS \\
\hline 5 & 31 & & & 5 & $\mathrm{~A}=1 \mathrm{~V}=1 \mathrm{M}=1 \mathrm{O}=1 \mathrm{C}=0 \mathrm{Ar}=1$ & VS \\
\hline 7 & 31 & female & hemorrhagic & 4 & $\mathrm{~A}=0 \mathrm{~V}=1 \mathrm{M}=1 \mathrm{O}=1 \mathrm{C}=0 \mathrm{Ar}=1$ & VS \\
\hline 8 & 39 & & & 6 & $\mathrm{~A}=1 \mathrm{~V}=2 \mathrm{M}=1 \mathrm{O}=1 \mathrm{C}=0 \mathrm{Ar}=2$ & VS \\
\hline 9 & 48 & & & 5 & $\mathrm{~A}=\mathrm{OV}=1 \mathrm{M}=2 \mathrm{O}=1 \mathrm{C}=0 \mathrm{Ar}=1$ & dead \\
\hline
\end{tabular}

CRS-R subscore: A, Auditory Scale; V, Visual Scale; M, Motor Scale; O, Oromotor/Visual Scale; C, Communication Scale; Ar, Arousal Scale.

(Riganello et al., 2008, 2010a), in particular too high or too low values of nuLF were associated to negative emotions.

In this study we tried to identify possible variations of the autonomic reactivity, specifically to the complexity of the musical stimulus, by analyzing the first $3 \mathrm{~min}$ of listening. The results were linked to the same length of the musical stimulation time, unlike the previous study, in which the HRV analysis was dependent also on the length of the tachogram.

The results showed differences between groups for HRV parameters, characterized generally by lower values in VS/UWS patients. This difference was significant for nuLF during the listening of Grieg and Mussorgsky, and for SampEn during the listening of Mussorgsky. Comparing the musical stimuli among them, the autonomic response was characterized by decreasing values in nuLF and SampEn in VS/UWS, when the musical complexity was higher. Such patients showed a shift of HRV parameters toward an increasing of vagal response, and contextually a reduction of heart rate complexity for increasing Formal Complexity and General Dynamics parameters. The different response to the musical stimuli was significant for SampEn, comparing Boccherini and Mussorgsky's musical samples. No similar response was observed in healthy subjects.

The experience of music listening is based on the idea that the music represents and induces emotions, which are, respectively, perceived and felt by listeners, although these two aspects may not coincide (Gabrielsson, 2002). The association of different psychological mechanisms, associated to the physiological correlates of the music listening, were suggested (Harrer and 

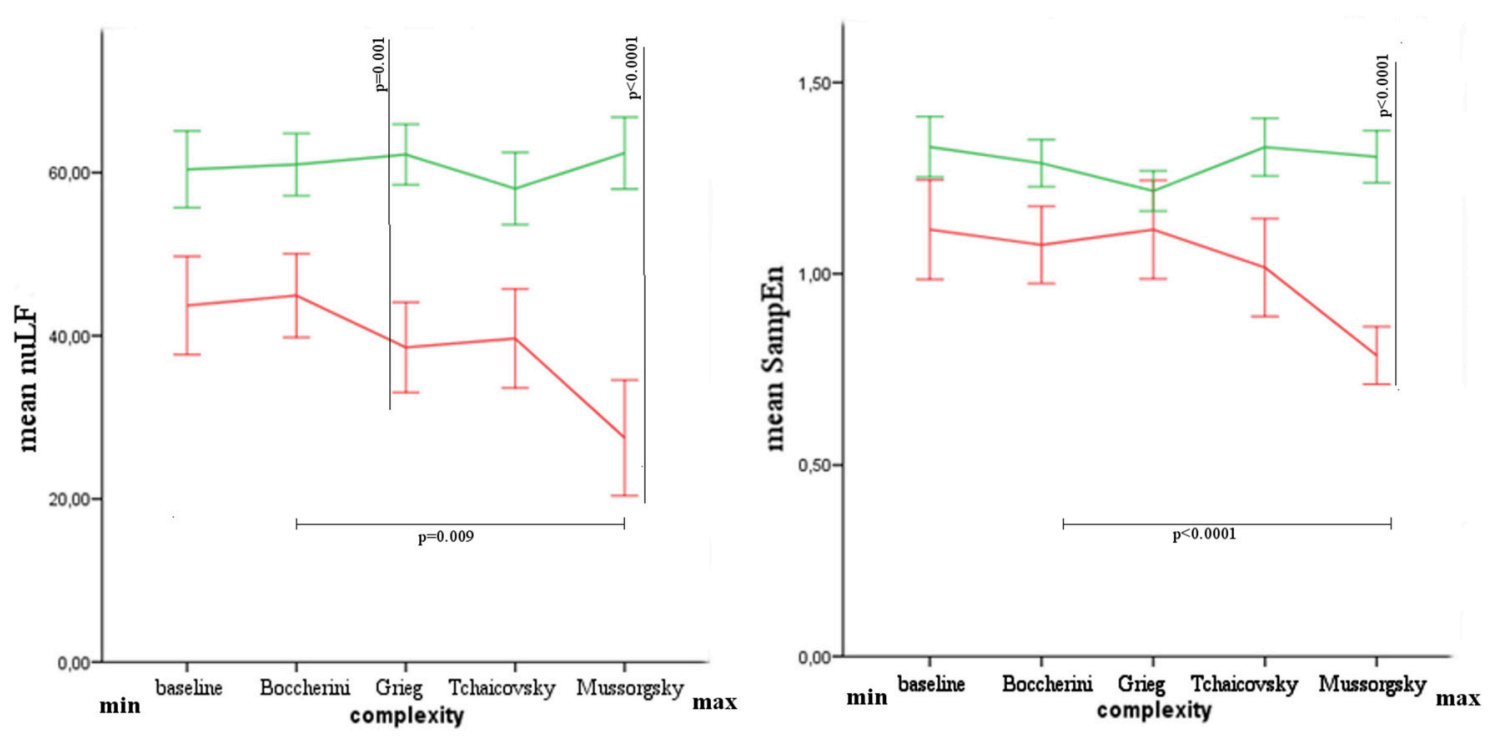

FIGURE 3 | Mean and Standard Error of nuLF and SampEn in healthy (green) and VS/UWS (red) groups. In the axis, from left to right, baseline and musical stimuli with increasing complex structure.

Harrer, 1968). Several modes of music listening were described as associated to conscious (e.g., structural analytic, associative oriented. ect.) or unconscious (e.g., associative emotional, motorkinetic, etc.) listening (Rauhe, 1975; Rösing, 1985; Behne, 1986). As reported, the music internal structure plays a primary role in the induction of emotions, and rhythmic aspects are considered the major determinants of physiological responses (Gomez and Danuser, 2007). More, the tonal variation was correlated to the psychophysiological happy/sad distinction (Khalfa et al., 2008).

It was shown that the applications of music in medicine can be used to stabilize vital signs and manage symptoms in the short-term (Hanser, 2014). The listening of classical music and of rock music or noise were related to a small variance or an increase/decrease of Mayer Wave components and Respiratory Sinus Arrhythmia components, respectively (Umemura and Honda, 1998). Relaxation and music therapy have been found effective modalities to reduce stress and anxiety in patients of a coronary care unit (Zimmerman et al., 1988; Guzzetta, 1989; Hanser, 2014). Music therapy enhanced parasympathetic activities and decreased Congestive Heart Failure by reducing plasma cytokine and catecholamine levels (Okada et al., 2009).

Changes in the HRV patterns of response indicative of enhanced activity of the cardiovascular system were observed after 14-day music therapy (Lee et al., 2011). Replicable changes in the sympathovagal balance have been identified in DoC patients during the passive listening of symphonic music (Riganello et al., 2008, 2010a,b), allowing to cluster the autonomic responses as indicative of positive or negative emotions in both VS/UWS and awake posttraumatic subjects. Music appears peculiarly efficient in promoting arousal and responsiveness in DoC (O'Kelly et al., 2013). The activation of the superior temporal gyrus, by music, can predict the evolution from VS/UWS (Okumura et al., 2014).
The heart rate reflects the sympathetic/parasympathetic interplay, with a dominant tonus at rest of parasympathetic nervous vagus innervating the intrinsic cardiac nervous system (Scherlag and Po, 2006), and projecting to the sinoatrial node, atrioventricular node, and atrial cardiac muscle. ANS mediates the bidirectional communication between heart function and the Central Nervous System (CNS; Kawashima, 2005; Riganello et al., 2014). This regulation depends on medullar centers, in particular the nucleus of solitary tract and rostroventrolateral medulla (Spyer and Gourine, 2009) that integrate sensory information from proprio-, chemo-, and mechanoreceptors and from the telencephalic and limbic systems. An increase of rate results from reduced vagal activity (Hainsworth, 1995) or sympathetic activity above the intrinsic levels operated by the sinoatrial node (Hainsworth, 1995). An integrated model has been proposed (usually referred to as the Central Autonomic Network, CAN; Benarroch, 1993), in which neuronal structures involved in cognitive, affective, emotional, and autonomic regulation are functionally linked to heart function. This complex brain-heart interaction with the bidirectional links between cortical, midbrain, and brainstem structures (Riganello et al., 2012a) include, among others, the orbitofrontal, ventromedial prefrontal, anterior cingulate, and insular cortices, basal ganglia, central nucleus of the amygdala, nucleus of the solitary tract, nucleus ambiguus, and periaqueductal gray matter. The interplay between autonomic control and the CNS is modeled as a functional setup connecting through feedback and feedforward loops the brainstem solitary tract nucleus with forebrain structures (Napadow et al., 2008; Lane et al., 2009; Riganello et al., 2012a).

Most of studies on HRV and music have been experimental rather than interventional, reporting significant changes in HRV as a function of musical mood (Etzel et al., 2006), genre 
(Bernardi et al., 2006), familiarity (Iwanaga et al., 2005), or tempo(Ellis, 2009; Fukumoto and Matsuo, 2010). Few reports exist of musical interventions that have included HRV as an index of autonomic function (Kemper et al., 2008; Okada et al., 2009; Ellis and Thayer, 2010; Roque et al., 2013a,b), and very few on musical stimuli and HRV in VS/UWS patients (Riganello et al., 2010a,b; Yen et al., 2010; Lee et al., 2011). However, it was suggested that the effect of music on cerebral processes in patients might reflect its capacity to act both on the external and internal neural networks supporting consciousness (Perrin et al., 2015). Again, it has been shown the benefit of classical and meditation music on patients hospitalized in intensive care medicine, whereas heavy metal or techno music were found not only ineffective, but possibly dangerous (Trappe, 2012). In these frames, it is important to define the correlations between musical structures and autonomic response to the musical stimuli, in order to have a correct approach to the stimulation of patients with DoC.

\section{CONCLUSIONS}

The music listening is a complex experience and the responsiveness to the musical stimuli is constituted by a strong individual variability (Hanser, 2014). However, the study of the musical parameters can help to define and

\section{REFERENCES}

Aboy, M., Cuesta-Frau, D., Austin, D., and Mico-Tormos, P. (2007). "Characterization of sample entropy in the context of biomedical signal analysis," in 29th Annual International Conference of the IEEE Engineering in Medicine and Biology Society, 2007 (Lyon: EMBS), 5942-5945.

Batchinsky, A. I., Salinas, J., Kuusela, T., Necsoiu, C., Jones, J., and Cancio, L. C. (2009). Rapid prediction of trauma patient survival by analysis of heart rate complexity: impact of reducing data set size. Shock Augusta Ga 32, 565-571. doi: 10.1097/SHK.0b013e3181a993dc

Behne, K.-E. (1986). Hörertypologien: zur Psychologie des Jugendlichen Musikgeschmacks. Regensburg: G. Bosse.

Benarroch, E. E. (1993). The central autonomic network: functional organization, dysfunction, and perspective. Mayo Clin. Proc. 68, 988-1001. doi: 10.1016/S0025-6196(12)62272-1

Bernardi, L., Porta, C., and Sleight, P. (2006). Cardiovascular, cerebrovascular, and respiratory changes induced by different types of music in musicians and non-musicians: the importance of silence. Heart 92, 445-452. doi: 10.1136/hrt.2005.064600

Biswas, A. K., Scott, W. A., Sommerauer, J. F., and Luckett, P. M. (2000). Heart rate variability after acute traumatic brain injury in children. Crit. Care Med. 28, 3907-3912. doi: 10.1097/00003246-20001200000030

Burr, R. L. (2007). Interpretation of normalized spectral heart rate variability indices in sleep research: a critical review. Sleep 30, 913-919.

Cancio, L. C., Batchinsky, A. I., Salinas, J., Kuusela, T., Convertino, V. A., Wade, C. E., et al. (2008). Heart-rate complexity for prediction of prehospital lifesaving interventions in trauma patients. J. Trauma Inj. Infect. Crit. Care 65, 813-819. doi: 10.1097/TA.0b013e3181848241

Crozier, J. B. (1974). Verbal and exploratory responses to sound sequences varying in uncertainty level. Stud. New Exp. Aesthet. 10, 27-90.

Dube, L., and Le Bel, J. (2003). The content and structure of laypeople's concept of pleasure. Cogn. Emot. 17, 263-295. doi: 10.1080/02699930302295

da Silva, S. A., Guida, H. L., dos SantosAntônio, A. M., Vanderlei, L. C., Ferreira, L. L., de Abreu, L. C., et al. (2014). Auditory stimulation with music influences make hypothesis about musical stimuli and modification of ANS.

The close relationship between the CAN structures and the music listening could play an important function in the use of music in DoC patients (Magee, 2005; O'Kelly and Magee, 2013; O'Kelly et al., 2013). Complex musical stimuli could reduce the effectiveness of the response too. In order to improve the approach by the musical stimulation, further investigations are required to better comprehend how the musical structures can modify the autonomic response in DoC patients.

\section{AUTHOR CONTRIBUTIONS}

All Authors equally contributed to the study design and preparation of the protocol as well as to the manuscript preparation. FR also performed the statistical analyses. The work reported in this paper has not been published previously, is not under consideration for publication elsewhere, and if accepted will not be published elsewhere including electronically in the same form, in English or in any other language, without the written consent of the copyright-holder. Its publication is approved by all authors and by the responsible authorities where the work was carried out. All Authors are employees of the Institute $\mathrm{S}$. Anna-RAN and the study was supported by the Institute itself, without external funding.

the geometric indices of heart rate variability in men. Int. Arch. Med. 7:27. doi: $10.1186 / 1755-7682-7-27$

Ellis, R. J. (2009). The Effect of Musical Tempo on Subjective and Physiological Indices of Affective Response. Doctoral dissertation, The Ohio State University. Available online at: https://etd.ohiolink.edu/

Ellis, R. J., and Thayer, J. F. (2010). Music and autonomic nervous system (dys)function. Music Percept. 27, 317-326. doi: 10.1525/mp.2010.27.4.317

Etzel, J. A., Johnsen, E. L., Dickerson, J., Tranel, D., and Adolphs, R. (2006). Cardiovascular and respiratory responses during musical mood induction. Int. J. Psychophysiol. 61, 57-69. doi: 10.1016/j.ijpsycho.2005.10.025

Fukumoto, M., and Matsuo, K. (2010). Effects of musical tempo on multiple subjective impressions. Int. J. Biom. 2, 124-133. doi: 10.1504/IJBM.2010.031792

Gabrielsson, A. (2002). Emotion perceived and emotion felt: same or different? Music. Sci. 5, 123-147. doi: 10.1177/10298649020050S105

Gabrielsson, A., and Juslin, P. N. (1996). Emotional expression in music performance: between the performer's intention and the listener's experience. Psychol. Music 24, 68-91. doi: 10.1177/0305735696241007

Giacino, J. T., and Kalmar, K. (2005). Diagnostic and prognostic guidelines for the vegetative and minimally conscious states. Neuropsychol. Rehabil. 15, 166-174. doi: 10.1080/09602010443000498

Giacino, J. T., Kalmar, K., and Whyte, J. (2004). The JFK coma recovery scalerevised: measurement characteristics and diagnostic utility. Arch. Phys. Med. Rehabil. 85, 2020-2029. doi: 10.1016/j.apmr.2004.02.033

Gibbons, J. D., and Chakraborti, S. (2011). "Nonparametric statistical inference," in International Encyclopedia of Statistical Science, ed M. Lovric (Berlin; Heidelberg: Springer), 977-979. Available online at: http://link.springer.com/referenceworkentry/10.1007/978-3-642-04898-2_420 (Accessed July 2, 2015).

Goldstein, B., Kempski, M. H., DeKing, D., Cox, C., DeLong, D. J., Kelly, M. M., et al. (1996). Autonomic control of heart rate after brain injury in children. Crit. Care Med. 24, 234-240. doi: 10.1097/00003246-19960200000009

Gomez, P., and Danuser, B. (2007). Relationships between musical structure and psychophysiological measures of emotion. Emotion 7, 377-387. doi: 10.1037/1528-3542.7.2.377 
Guzzetta, C. E. (1989). Effects of relaxation and music therapy on patients in a coronary care unit with presumptive acute myocardial infarction. Heart Lung J. Crit. Care 18, 609-616.

Hainsworth, R. (1995). "The control and physiological importance of heart rate," in Heart Rate Variability, eds M. Malik and A. J. Camm (Armonk, NY: Futura Publishing Company, Inc.), 3-19.

Hajizadeh, S., Abbasi, A., and Goshvarpour, A. (2015). Empirical mode decomposition-based analysis of heart rate signal affected by iranian music. Appl. Med. Inform. 37, 11-20. Available online at: http://ami.info.umfcluj.ro/ index.php/AMI/article/view/545

Hanser, S. B. (2014). Music therapy in cardiac health care: current issues in research. Cardiol. Rev. 22, 37-42. doi: 10.1097/CRD.0b013e318291c5fc

Harrer, G., and Harrer, H. (1968). Music, emotion and the autonomic nervous system. Wien. Med. Wochenschr. 118, 966-971.

Hemphill, J. F. (2003). Interpreting the magnitudes of correlation coefficients. Am. Psychol. 58, 78-79. doi: 10.1037/0003-066X.58.1.78

Hodges, D. A. (1980). Handbook of Music Psychology. Washington, DC: National Association for Music Therapy.

Holbrook, M. B., and Anand, P. (1990). Effects of tempo and situational arousal on the listener's perceptual and affective responses to music. Psychol. Music 18, 150-162. doi: 10.1177/0305735690182004

Imberty, M. (1976). Signification and Meaning in Music. Montreal, QC: Groupe de Recherches en Sémiologie Musicale, Faculté de Musique, Université de Montréal.

Imberty, M. (1997). Formes de la répétition et formes des affects du temps dans l'expression musicale. Music. Sci. 1, 33-62.

Iwanaga, M., Kobayashi, A., and Kawasaki, C. (2005). Heart rate variability with repetitive exposure to music. Biol. Psychol. 70, 61-66. doi: 10.1016/j.biopsycho.2004.11.015

Juslin, P. N. (1997). Emotional communication in music performance: a functionalist perspective and some data. Music Percept. 14, 383-418. doi: $10.2307 / 40285731$

Juslin, P. N. (2000). Cue utilization in communication of emotion in music performance: relating performance to perception. J. Exp. Psychol. Hum. Percept. Perform. 26, 1797-1813. doi: 10.1037/0096-1523.26.6.1797

Juslin, P. N., and Sloboda, J. A. (2010). Handbook of Music and Emotion: Theory, Research, Applications. Oxford: Oxford University Press.

Kaplan, D. T., Furman, M. I., Pincus, S. M., Ryan, S. M., Lipsitz, L. A., and Goldberger, A. L. (1991). Aging and the complexity of cardiovascular dynamics. Biophys. J. 59, 945. doi: 10.1016/S0006-3495(91)82309-8

Kawashima, T. (2005). The autonomic nervous system of the human heart with special reference to its origin, course, and peripheral distribution. Anat. Embryol. (Berl) 209, 425-438. doi: 10.1007/s00429-005-0462-1

Kemper, K. J., Hamilton, C. A., McLean, T. W., and Lovato, J. (2008). Impact of music on pediatric oncology outpatients. Pediatr. Res. 64, 105-109. doi: 10.1203/PDR.0b013e318174e6fb

Keren, O., Yupatov, S., Radai, M. M., Elad-Yarum, R., Faraggi, D., Abboud, S., et al. (2005). Heart rate variability (HRV) of patients with traumatic brain injury (TBI) during the post-insult sub-acute period. Brain Inj. 19, 605-611. doi: 10.1080/02699050400024946

Khalfa, S., Roy, M., Rainville, P., Dalla Bella, S., and Peretz, I. (2008). Role of tempo entrainment in psychophysiological differentiation of happy and sad music? Int. J. Psychophysiol. 68, 17-26. doi: 10.1016/j.ijpsycho.2007.12.001

Khandoker, A. H., Jelinek, H. F., and Palaniswami, M. (2009). Identifying diabetic patients with cardiac autonomic neuropathy by heart rate complexity analysis. Biomed. Eng. OnLine 8:3. doi: 10.1186/1475-925x-8-3

Koelsch, S. (2005). Neural substrates of processing syntax and semantics in music. Curr. Opin. Neurobiol. 15, 207-212. doi: 10.1016/j.conb.2005.03.005

Koelsch, S., Fritz, T. V., Cramon, D. Y., Müller, K., and Friederici, A. D. (2006). Investigating emotion with music: an fMRI study. Hum. Brain Mapp. 27, 239-250. doi: 10.1002/hbm.20180

Lane, R., McRae, K., Reiman, E. M., Chen, K., Ahern, G. L., and Thayer, J. (2009). Neural correlates of heart rate variability during emotion. Neuroimage 44, 213-222. doi: 10.1016/j.neuroimage.2008.07.056

Lee, Y.-C., Lei, C.-Y., Shih, Y.-S., Zhang, W.-C., Wang, H.-M., Tseng, C.-L., et al. (2011). HRV response of vegetative state patient with music therapy. Conf. Proc. IEEE Eng. Med. Biol. Soc. 2011, 1701-1704. doi: 10.1109/IEMBS.2011.60 90488
Magee, W. L. (2005). Music therapy with patients in low awareness states: approaches to assessment and treatment in multidisciplinary care. Neuropsychol. Rehabil. 15, 522-536. doi: 10.1080/09602010443000461

Malliani, A. (1999). The pattern of sympathovagal balance explored in the frequency domain. Physiology 14, 111-117.

Meyer, L. B. (2008). Emotion and Meaning in Music. Chicago, IL: University of Chicago Press.

Montano, N., Porta, A., Cogliati, C., Costantino, G., Tobaldini, E., Casali, K. R., et al. (2009). Heart rate variability explored in the frequency domain: a tool to investigate the link between heart and behavior. Neurosci. Biobehav. Rev. 33, 71-80. doi: 10.1016/j.neubiorev.2008.07.006

Mukherjee, S., Palit, S. K., Banerjee, S., and Bhattacharya, D. K. (2015). "A comparative study on three different types of music based on same indian raga and their effects on human autonomic nervous systems," in Chaos, Complexity and Leadership 2013, eds Ş. Ş. Erçetin and S. Banerjee (Cham: Springer International Publishing), 243-254. Available at: http://link.springer.com/10.1007/978-3-319-09710-7_21 (Accessed September, 10, 2015).

Mundry, R., and Fischer, J. (1998). Use of statistical programs for nonparametric tests of small samples often leads to incorrect P values: examples from animal behaviour. Anim. Behav. 56, 256-259. doi: 10.1006/anbe.1998.0756

Napadow, V., Dhond, R., Conti, G., Makris, N., Brown, E. N., and Barbieri, R. (2008). Brain correlates of autonomic modulation: combining heart rate variability with fMRI. Neuroimage 42, 169-177. doi: 10.1016/j.neuroimage.2008.04.238

Niskanen, J.-P., Tarvainen, M. P., Ranta-aho, P. O., and Karjalainen, P. A. (2004). Software for advanced HRV analysis. Comput. Methods Programs Biomed. 76, 73-81. doi: 10.1016/j.cmpb.2004.03.004

Norris, P. R., Ozdas, A., Cao, H., Williams, A. E., Harrell, F. E., Jenkins, J. M., et al. (2006). Cardiac uncoupling and heart rate variability stratify ICU patients by mortality: a study of 2088 trauma patients. Ann. Surg. 243, 804-812; discussion 812-814. doi: 10.1097/01.sla.0000219642.92637.fd

O’Kelly, J., James, L., Palaniappan, R., Taborin, J., Fachner, J., and Magee, W. L. (2013). Neurophysiological and behavioral responses to music therapy in vegetative and minimally conscious states. Front. Hum. Neurosci. 7: 884. doi: 10.3389 /fnhum.2013.00884

O'Kelly, J., and Magee, W. L. (2013). Music therapy with disorders of consciousness and neuroscience: the need for dialogue. Nord. J. Music Ther. 22, 93-106. doi: 10.1080/08098131.2012.709269

Ockelford, A. (2008). Review article: D. HURON, Sweet Anticipation: Music and the Psychology of Expectation. Cambridge, MA: The MIT Press (A Bradford Book), 2006, 476, 108 illus. ISBN 0-262-08345-0 (hbk) \$40/£25.95. Psychol. Music 36, 367-382. doi: 10.1177/0305735608094506

Okada, K., Kurita, A., Takase, B., Otsuka, T., Kodani, E., Kusama, Y., et al. (2009). Effects of music therapy on autonomic nervous system activity, incidence of heart failure events, and plasma cytokine and catecholamine levels in elderly patients with cerebrovascular disease and dementia. Int. Heart. J. 50, 95-110. doi: 10.1536/ihj.50.95

Okumura, Y., Asano, Y., Takenaka, S., Fukuyama, S., Yonezawa, S., Kasuya, Y., et al. (2014). Brain activation by music in patients in a vegetative or minimally conscious state following diffuse brain injury. Brain Inj. 28, 944-950. doi: 10.3109/02699052.2014.888477

Orini, M., Bailón, R., Enk, R., Koelsch, S., Mainardi, L., and Laguna, P. (2010). A method for continuously assessing the autonomic response to music-induced emotions through HRV analysis. Med. Biol. Eng. Comput. 48, 423-433. doi: 10.1007/s11517-010-0592-3

Papaioannou, V. E., Maglaveras, N., Houvarda, I., Antoniadou, E., and Vretzakis, G. (2006). Investigation of altered heart rate variability, nonlinear properties of heart rate signals, and organ dysfunction longitudinally over time in intensive care unit patients. J. Crit. Care 21, 95-103; discussion 103-104. doi: 10.1016/j.jcrc.2005.12.007

Papaioannou, V., Giannakou, M., Maglaveras, N., Sofianos, E., and Giala, M. (2008). Investigation of heart rate and blood pressure variability, baroreflex sensitivity, and approximate entropy in acute brain injury patients. J. Crit. Care 23, 380-386. doi: 10.1016/j.jcrc.2007.04.006

Perez-Lloret, S., Diez, J., Domé, M. N., Delvenne, A. A., Braidot, N., Cardinali, D. P., et al. (2014). Effects of different "relaxing" music styles on the autonomic nervous system. Noise Health 16, 279-284. doi: 10.4103/1463-1741.140507 
Perrin, F., Castro, M., Tillmann, B., and Luauté, J. (2015). Promoting the use of personally relevant stimuli for investigating patients with disorders of consciousness. Front. Psychol. 6:1102. doi: 10.3389/fpsyg.2015.01102

Pincus, S. M., and Goldberger, A. L. (1994). Physiological time-series analysis: what does regularity quantify? Am. J. Physiol.-Heart Circ. Physiol. 266, H1643-H1656.

Porta, A., Guzzetti, S., Montano, N., Pagani, M., Somers, V., Malliani, A., et al. (2000). Information domain analysis of cardiovascular variability signals: evaluation of regularity, synchronisation and co-ordination. Med. Biol. Eng. Comput. 38, 180-188. doi: 10.1007/BF02344774

Rapenne, T., Moreau, D., Lenfant, F., Vernet, M., Boggio, V., Cottin, Y., et al. (2001). Could heart rate variability predict outcome in patients with severe head injury? A pilot study. J. Neurosurg. Anesthesiol. 13, 260-268.

Rauhe, H. (1975). Rezeptionspsychologischer aspekt: kategoriale erfassung musikalischer Hörvorgänge durch Entwicklung korrespondierender rezeptionskategorien und analysen ihrer Bedingungszusammenhänge. 1975, 137-145.

Richman, J. S., and Moorman, J. R. (2000). Physiological time-series analysis using approximate entropy and sample entropy. Am. J. Physiol.-Heart Circ. Physiol. 278, H2039-H2049.

Riganello, F., Candelieri, A., Quintieri, M., Conforti, D., and Dolce, G. (2010a). Heart rate variability: an index of brain processing in vegetative state? An artificial intelligence, data mining study. Clin. Neurophysiol. 121, 2024-2034. doi: 10.1016/j.clinph.2010.05.010

Riganello, F., Candelieri, A., Quintieri, M., and Dolce, G. (2010b). Heart rate variability, emotions, and music. J. Psychophysiol. 24, 112-119. doi: 10.1027/0269-8803/a000021

Riganello, F., Dolce, G., and Sannita, W. (2012a). Heart rate variability and the central autonomic network in the severe disorder of consciousness. J. Rehabil. Med. 44, 495-501. doi: 10.2340/16501977-0975

Riganello, F., Garbarino, S., and Sannita, W. G. (2012b). Heart rate variability, homeostasis, and brain function: a tutorial and review of application. J. Psychophysiol. 26, 178-203. doi: 10.1027/0269-8803/ a 000080

Riganello, F., Giuliano, D., Garbarino, S., and Sannita, W. G. (2014). Heart rate variability and the two-way interaction between CNS and the central autonomic network. Exp. Clin. Cardiol. 20, 5584-5595. Available online at: http://www. researchgate.net/publication/266206042

Riganello, F., Quintieri, M., Candelieri, A., Conforti, D., and Dolce, G. (2008). Heart rate response to music: an artificial intelligence study on healthy and traumatic brain-injured subjects. J. Psychophysiol. 22, 166-174. doi: 10.1027/0269-8803.22.4.166

Riordan, W. P. Jr., Norris, P. R., Jenkins, J. M., and Morris, J. A. Jr. (2009). Early loss of heart rate complexity predicts mortality regardless of mechanism, anatomic location, or severity of injury in 2178 trauma patients. J. Surg. Res. 156, 283-289. doi: 10.1016/j.jss.2009.03.086

Roque, A. L., Valenti, V. E., Guida, H. L., Campos, M. F., Knap, A., Vanderlei, L. C. M., et al. (2013a). The effects of auditory stimulation with music on heart rate variability in healthy women. Clinics 68, 960-967. doi: 10.6061/clinics/2013(07)12

Roque, A. L., Valenti, V. E., Guida, H. L., Campos, M. F., Knap, A., Vanderlei, L. C., et al. (2013b). The effects of different styles of musical auditory stimulation on cardiac autonomic regulation in healthy women. Noise Health 15, 281. doi: 10.4103/1463-1741.113527

Rosenthal, R. (1991). Effect sizes: pearson's correlation, its display via the BESD, and alternative indices. Am. Psychol. 46, 1086-1087. doi: 10.1037/0003066X.46.10.1086

Rösing, H. (1985). Grundzüge musikalischen hörens und psychische wirkungen funktioneller Musik 1985, 39-56.

Ryan, M. L., Thorson, C. M., Otero, C. A., Vu, T., and Proctor, K. G. (2011). Clinical applications of heart rate variability in the triage and assessment of traumatically injured patients. Anesthesiol. Res. Pract. 2011:416590. doi: $10.1155 / 2011 / 416590$
Scherlag, B. J., and Po, S. (2006). The intrinsic cardiac nervous system and atrial fibrillation. Curr. Opin. Cardiol. 21, 51-54. doi: 10.1097/01.hco.0000198980.40390.e4

Siegel, S. (1956). Nonparametric Statistics for the Behavioral Sciences. New York, NY: McGraw-Hill.

Smith, J. D., and Melara, R. J. (1990). Aesthetic preference and syntactic prototypicality in music:'tis the gift to be simple. Cognition 34, 279-298. doi: 10.1016/0010-0277(90)90007-7

Spyer, K. M., and Gourine, A. V. (2009). Chemosensory pathways in the brainstem controlling cardiorespiratory activity. Philos. Trans. R. Soc. B Biol. Sci. 364, 2603-2610. doi: 10.1098/rstb.2009.0082

Task Force of the European Society of Cardiology and the North American Society of Pacing and Electrophysiology. (1996). Heart rate variability standards of measurement, physiological interpretation, and clinical use. Eur. Heart J. 17, 354-381.

Tanizaki, H. (1997). Power comparison of non-parametric tests: small-sample properties from monte carlo experiments. J. Appl. Stat. 24, 603-632. doi: $10.1080 / 02664769723576$

Tarvainen, M. P., Niskanen, J.-P., Lipponen, J. A., Ranta-Aho, P. O., and Karjalainen, P. A. (2014). Kubios HRV-heart rate variability analysis software. Comput. Methods Programs Biomed. 113, 210-220. doi: 10.1016/j.cmpb.2013.07.024

Tillmann, B. (2005). Implicit investigations of tonal knowledge in nonmusician listeners. Ann. N.Y. Acad. Sci. 1060, 100-110. doi: 10.1196/annals. 1360.007

Trappe, H.-J. (2012). Role of music in intensive care medicine. Int. J. Crit. Illn. Inj. Sci. 2, 27-31. doi: 10.4103/2229-5151.94893

Umemura, M., and Honda, K. (1998). Influence of music on heart rate variability and comfort-a consideration through comparison of music and noise. J. Hum. Ergol. (Tokyo) 27, 30-38.

Vitz, P. C. (1966). Affect as a function of stimulus variation. J. Exp. Psychol. 71, 74-79. doi: 10.1037/h0022619

Voss, A., Kurths, J., Kleiner, H. J., Witt, A., Wessel, N., Saparin, P., et al. (1996). The application of methods of non-linear dynamics for the improved and predictive recognition of patients threatened by sudden cardiac death. Cardiovasc. Res. 31, 419-433. doi: 10.1016/0008-6363(96)00008-9

Wijnen, V. J., Heutink, M., van Boxtel, G. J., Eilander, H. J., and de Gelder, B. (2006). Autonomic reactivity to sensory stimulation is related to consciousness level after severe traumatic brain injury. Clin. Neurophysiol. 117, 1794-1807. doi: 10.1016/j.clinph.2006.03.006

World Medical Association (2001). World Medical Association Declaration of Helsinki. Ethical principles for medical research involving human subjects. Bull. World Health Organ. 79, 373-374.

Yen, B. S., Wang, H.-M., Hou, M. C., Huang, S.-C., Chou, L.-C., Hsu, S.-Y., et al. (2010). "The relationship between music processing and electrocardiogram (ECG) in vegetative state (VS)," in Proceedings of 2010 IEEE International Symposium on Circuits and Systems (Paris), 2239-2242. doi: 10.1109/ISCAS.2010.5537211

Zimmerman, L. M., Pierson, M. A., and Marker, J. (1988). Effects of music on patient anxiety in coronary care units. Heart Lung J. Crit. Care 17, 560-566.

Conflict of Interest Statement: The authors declare that the research was conducted in the absence of any commercial or financial relationships that could be construed as a potential conflict of interest.

Copyright (๑) 2015 Riganello, Cortese, Arcuri, Quintieri and Dolce. This is an openaccess article distributed under the terms of the Creative Commons Attribution License (CC BY). The use, distribution or reproduction in other forums is permitted, provided the original author(s) or licensor are credited and that the original publication in this journal is cited, in accordance with accepted academic practice. No use, distribution or reproduction is permitted which does not comply with these terms. 